\title{
Co-cultivation of rat pneumocytes and bovine endothelial cells on a liquid-air interface
}

\author{
N. Gueven*, B. Glatthaar*, H-G. Manke**, H. Haemmerle*
}

Co-cultivation of rat pneumocytes and bovine endothelial cells on a liquid-air interface. N. Gueven, B. Glatthaar, H-G. Manke, H. Haemmerle. CERS Journals Ltd 1996.

ABSTRACT: The blood-air barrier is a most important functional element of the lung but little information is available about the cells constituting this barrier in vivo. The aim of the present study was to create an in vitro model of the blood-air barrier that would allow investigation of cellular interactions and alveolar metabolism, and would be suitable for in vitro drug screening.

Rat pneumocytes and bovine microvascular endothelial cells were grown on opposite sides of microporous polycarbonate filters, as immersion, perfusion and liquidair interface (LAI) cultures. The effects of culture conditions on cell morphology were examined by light and transmission electron microscopy. For immersion and perfusion co-cultures, both compartments were supplied with culture medium. In contrast, for liquid-air interface studies, only the endothelial cell compartment was continuously supplied with serum-free medium, whilst the type II pneumocytes were ventilated with air.

The pneumocytes lost their morphological characteristics when using immersion or perfusion co-cultures. Under liquid-air interface conditions, they retained most of their characteristic morphological features when compared to the intact bloodair barrier. A subset of primary type II pneumocytes retained its differentiated phenotype, with cuboidal morphology, lamellar bodies and apical microvilli. These type II pneumocytes appeared to be connected by tight junctions to cells expressing morphological characteristics of type I pneumocytes. As shown herein, the liquid-air interface co-culture possesses many morphological characteristics of the intact blood-air barrier.

In summary, this article describes the design of an artificial blood-air barrier, in which rat pneumocytes were cultivated with bovine microvascular endothelial lung cells on opposing sides of a microporous polycarbonate filter. We conclude that it might be a promising in vitro model for studies of molecular transport via the bloodair barrier, the investigation of repair mechanisms after alveolar injury, or as an in vitro screening system.

Eur Respir J., 1996, 9, 968-975.
*Naturwissenschaftliches und Medizinisches Institut an der Universitaet Tuebingen in Reutlingen (NMI), Reutlingen, FRG.

**Thorax-Klinik der LVA Baden, HeidelbergRohrbach, FRG.

Correspondence: H. Haemmerle

Naturwissenschaftliches und Medizinisches Institut an der Universitaet Tuebingen in Reutlingen (NMI)

Eberhardstr. 29

D-72762 Reutlingen

FRG

Keywords: Blood-air barrier co-culture

microvascular endothelial cells

perfusion

pneumocytes type II

Received: December 141994

Accepted after revision January 131996

This work was supported by the "Bundesministerium fuer Forschung und Technologie", grant No. 01 KE 8802/5.
The lung is the largest surface of the human organism exposed to the environment. Therefore, all cellular reactions (immunological defence, etc.) are very likely to be regulated by highly organized processes of intercellular signalling between the various cell types of this system. The surface of the alveolar system of the lung is covered by type I flattened pneumocytes and type II pneumocytes (TII). Together with the underlying capillary endothelial cells, they secrete components of a common basal membrane. This arrangement of epithelial cells, basal membrane and endothelial cells is termed the blood-air barrier (fig. 1). At its thinnest, it is $1-2 \mu \mathrm{m}$ thin to facilitate gas diffusion and in the human has an area of $70-100 \mathrm{~m}^{2}$.

Several attempts have been made to study the functional and metabolic properties of the lung in vitro. Various co-culture models have been presented to elucidate the interactions of distinct lung cells [1-3]. These coculture systems were designed to investigate the interaction between TII cells and fibroblasts, and between TII cells and macrophages. To our knowledge, co-cultivation of pure cultures of TII cells and microvascular endothelial cells (MEC) on opposing sides of a porous filter has not previously been reported.

The aim of the present study was to establish an in vitro model of the blood-air barrier which mimics the fundamental cellular arrangement of the alveolar region in vitro. Based on the immersion co-culture, we designed a perfusion co-culture and finally a liquid-air interface (LAI) co-culture system. From our morphological results, the LAI culture system seems to be suitable as an in vitro model of the blood-air barrier and, therefore, a good tool to analyse the structural and functional behaviour of alveolar lung cells in a healthy state, as well as in the processes of regeneration, repair and disease.

\section{Material and methods}

\section{Isolation of cells}

Isolation, identification and viability of TII. TII cells were isolated by a modification of the method of DoBBS 

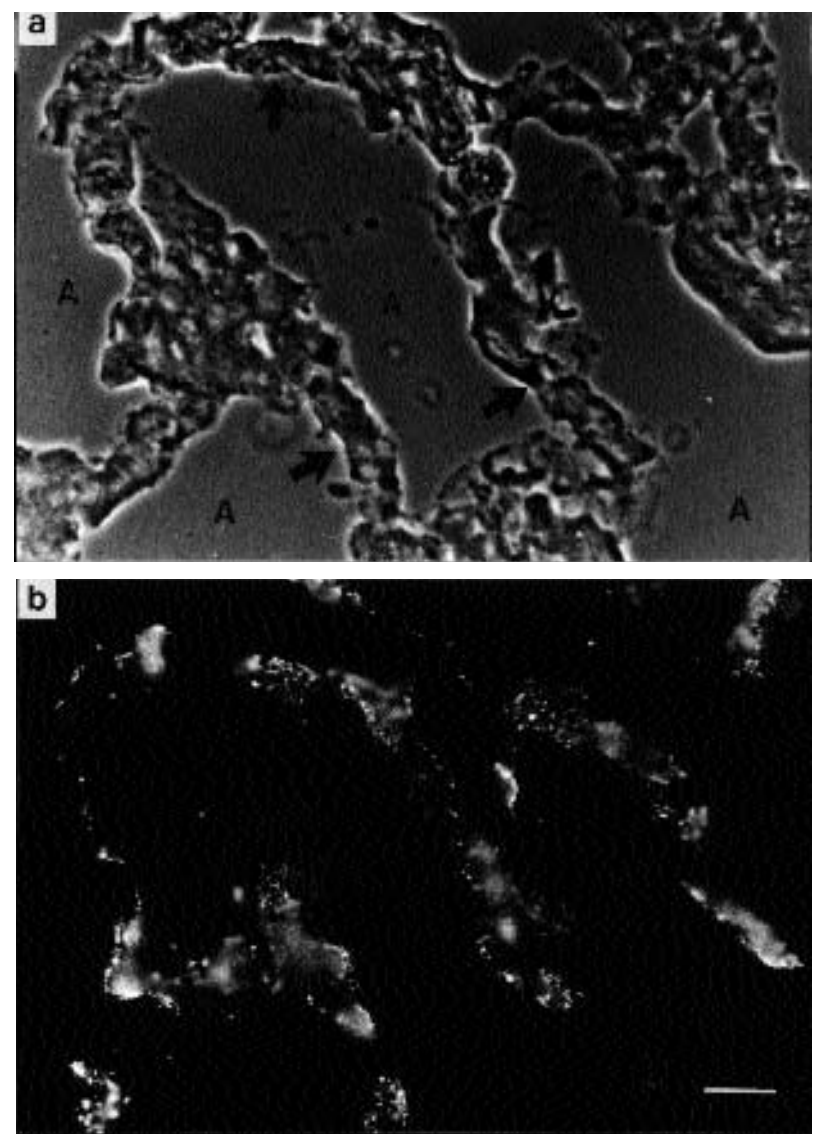

Fig. 1. - a) Phase contrast image of the alveolar region of the bovine lung. The alveoli (A) are surrounded by septa (arrows) containing the capillaries. The enlarged tissue regions are composed mainly of lung fibroblasts and extracellular matrix. b) Immunohistochemical localization of factor VII-related antigen in the region shown in (a) by a polyclonal antibody. Regions with mainly lung fibroblasts do not show any specific staining. Diffuse fluorescence results from granules above the plane of focus of the objective. (Internal scale bar $=20 \mu \mathrm{m}$ ).

et al. [4]. Two balanced salt solutions were used: Solution $1\left(\mathrm{pH} 7.4\right.$ at $22^{\circ} \mathrm{C}$ ) containing $140 \mathrm{mmol} \cdot \mathrm{L}^{-1} \mathrm{NaCl}$, $5 \mathrm{mmol} \cdot \mathrm{L}^{-1} \mathrm{KCl}, 2.5 \mathrm{mmol} \cdot \mathrm{L}^{-1} \mathrm{Na}_{2} \mathrm{HPO}_{4}, 10 \mathrm{mmol} \cdot \mathrm{L}^{-1}$ $\mathrm{N}$-2-hydroxyethylpiperazine-N'-2-ethanesulphonic acid (HEPES) buffer, $6 \mathrm{mmol} \cdot \mathrm{L}^{-1}$ glucose, $0.2 \mathrm{mmol} \cdot \mathrm{L}^{-1}$ ethyleneglycol-bis(b-aminoethylether) N,N,N',N', tetra-aceticacid (EGTA). Solution 2 containing $140 \mathrm{mmol} \cdot \mathrm{L}^{-1} \mathrm{NaCl}$, $5 \mathrm{mmol} \cdot \mathrm{L}^{-1} \mathrm{KCl}, 2.5 \mathrm{mmol} \cdot \mathrm{L}^{-1} \mathrm{Na}_{2} \mathrm{HPO}_{4}, 10 \mathrm{mmol} \cdot \mathrm{L}^{-1}$ HEPES buffer, $6 \mathrm{mmol} \cdot \mathrm{L}^{-1}$ glucose, $2 \mathrm{mmol} \cdot \mathrm{L}^{-1} \mathrm{CaCl}_{2}$ and $1.3 \mathrm{mmol} \cdot \mathrm{L}^{-1} \mathrm{MgSO}_{4}$. Rats (Sprague-Dawley 180 $200 \mathrm{~g}$ ) where anaesthetized with chloralhydrate solution (7\% dissolved in water; $7.5 \mathrm{~mL} \cdot \mathrm{kg}^{-1}$ body weight i.p.). Pulmonary blood vessels were perfused via the right heart ventricle with Solution 1 until the lung tissue became clear white to transparent. The lungs were removed from the thorax and lavaged eight times with solution, introduced via the trachea, to remove alveolar macrophages. The lungs were then filled with dispase solution (Grade II; $10 \mathrm{U} \cdot \mathrm{mL}^{-1}$ dissolved in Solution 2; Boehringer Mannheim, Mannheim, FRG) and incubated at $37^{\circ} \mathrm{C}$ whilst gently shaking. Forty millilitres of dispase solution were allowed to rinse through the lung tissue for $25 \mathrm{~min}$.

Thereafter, the lung tissue was minced into pieces of about $1 \mathrm{~mm}^{3}$ and subsequently filtered through two layers of gauze, $0.1 \mathrm{~mm}$ and $0.02 \mathrm{~mm}$ of nylon mesh. This crude cell suspension yielded about $2-3 \times 10^{7}$ cells.lung- ${ }^{-1}$ with a viability of over $90 \%$, as determined by staining with 5-(and 6-)-carboxyfluorescein-diacetate-succinimidyl-ester (CFSE; Molecular Probes, Eugene, USA) [5]. In order to separate TII cells from cells of the immune system and from fibroblasts, the method of "panning" was applied as follows. The cell suspension was poured onto rat immunoglobulin $\mathrm{G}$ ( $\mathrm{IgG}$ )-coated bacteriological culture dishes $(5 \mathrm{~mL}$ solution with $1.5 \mathrm{mg} \mathrm{IgG}$ per culture dish of $78.5 \mathrm{~cm}^{2}$ ). After $2 \mathrm{~h}$, the TII cells still remained in the supernatant, while the majority of other cell types adhered to the coated culture dish. The cell suspension obtained $\left(8-15 \times 10^{6}\right.$ cells.lung-1) contained 90-95\% TII cells, as determined by the modified Papanicolaou stain [4] (fig. 2a) and transmission electron microscopy (TEM) [6]. The viability of these cells, as tested by CFSE staining, was about $95 \%$. Only freshly isolated TII cells were used for the experiments.

Isolation, identification and viability of MEC cells. Distal ends of lung segments of freshly slaughtered cattle were used for cell isolation. Selected lung segments (50-150 g) were perfused with phosphate-buffered saline (PBS) via the arteria pulmonalis until the fluid emanating from the pulmonary vein became transparent (perfusion pressure $20 \mathrm{mmHg}$ ). Subsequent perfusion was performed with dispase solution (2.4 U. $\mathrm{mL}^{-1}$ dissolved in PBS) at $37^{\circ} \mathrm{C}$ for $10 \mathrm{~min}$ followed by a further perfusion with PBS until the flow ceased at $20 \mathrm{mmHg}$ due to tissue disintegration. Isolated cells were layered onto a discontinuous percoll-gradient, where the endothelial cells could be concentrated with a ultracentrifuge (Sorvall OTD-C; Du Pond, Bad Homburg, FRG; $2 \mathrm{~h}$ at 20,000 rpm in an AH-629 rotor) at a density of $1.064 \mathrm{~kg} \cdot \mathrm{L}^{-1}$. Approximately $2-4 \times 10^{6}$ cells with a viability of over $90 \%$ and a purity of more than $95 \%$, as determined by detection of factor VIII-related antigen expression (fig. 2b) (anti-factor VIII; Behringwerke, Marburg, FRG) were obtained from each lung segment. For primary endothelial cultures, a mixture of 64\% Ham F12 and 16\% Dulbeccos modified Eagles medium (DMEM; Gibco, Eggenstein, FRG) was used, supplemented with $20 \%$ foetal calf serum (FCS), $100 \mathrm{U} \cdot \mathrm{mL}^{-1}$ penicillin and $100 \mu \mathrm{g} \cdot \mathrm{mL}^{-1}$ streptomycin. The cells were plated on collagen type 1-coated culture dishes. To avoid overgrowth of endothelial cells by contaminating fibroblasts, the primary culture was seeded in clonal densities, followed by isolation and subculture of endothelial clones. The ability to show angiotensin-converting enzyme activity (Boehringer Mannheim Kit No. 789011; Mannheim, FRG) and to express factor VIII-related antigen were tested and selected cell populations with high levels of specific activities were cryoconserved in liquid nitrogen for further experiments. For co-culture experiments, the thawed cells were passaged only once. As a consequence of the isolation procedure, methods of characterization and ultrastructure, it was concluded that the isolated cells originated from the lung microvasculature [7].

Plating efficiency of isolated cells. An aliquot of isolated cells was plated on culture dishes and stained with the vital dye CFSE after $24 \mathrm{~h}$. The ratio of positively stained (=vital) cells to the total number of initially seeded cells, as determined by epifluorescent microscopy, was defined as plating efficiency. 

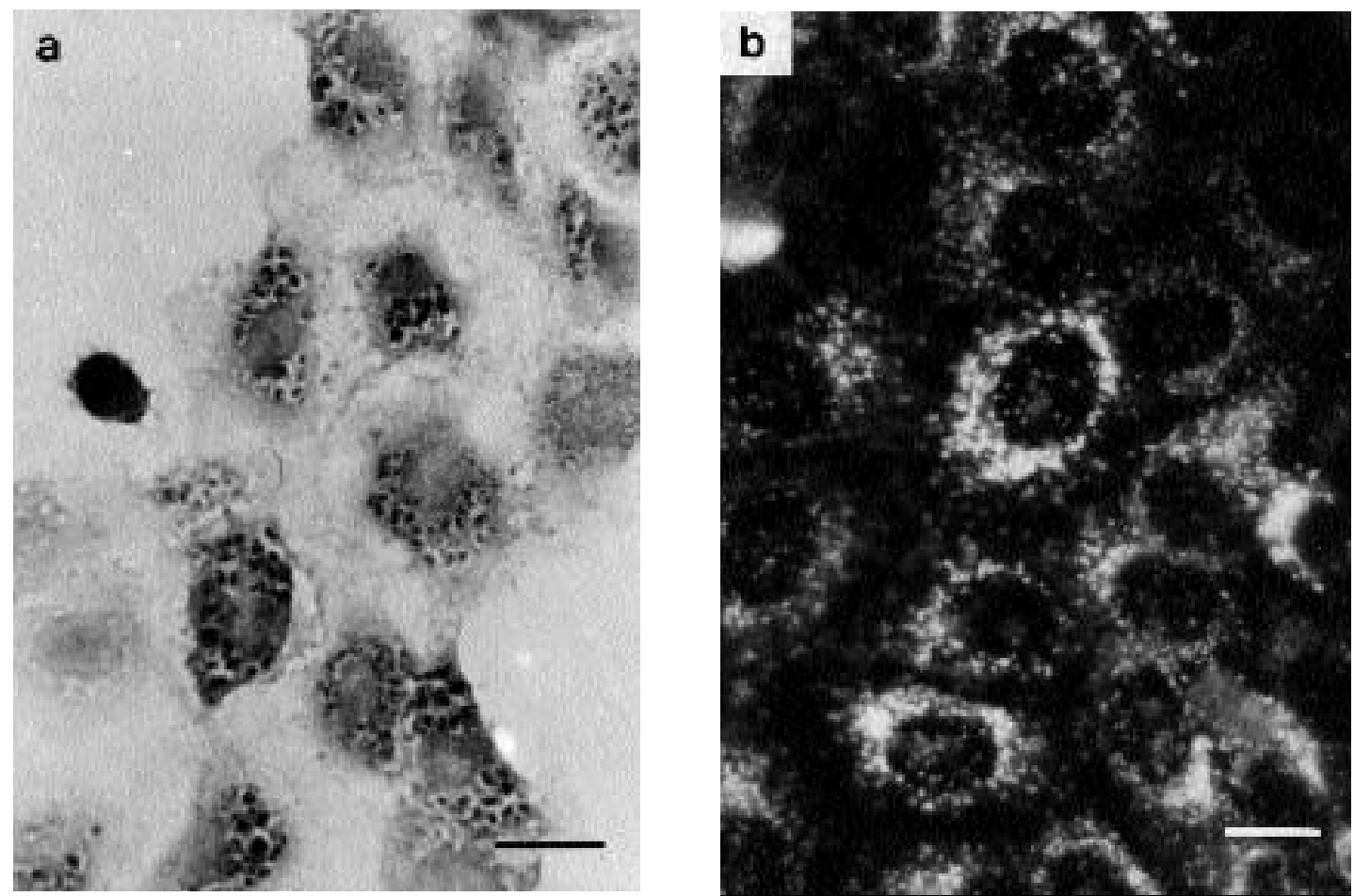

Fig. 2. - a) Air-dried pneumocyte type II cultures stained with the modified Papanicolaou staining method, $24 \mathrm{~h}$ after isolation. Dark lamellar bodies are visible around the nucleus. (Bright field microscopy; internal scale bar $=20 \mu \mathrm{m}$ ). b) Bovine microvascular endothelial cells stained with anti-factor VIII-antiserum. Granules appear to be concentrated predominantly but not exclusively in the perinuclear space. (Immunofluorescence microscopy; internal scale bar $=20 \mu \mathrm{m}$ ).

\section{Co-cultivation of TII and MEC}

Pretreatment of polycarbonate filter material. Nuclepore $\overparen{T M}$ (Nuclepore, Tuebingen, FRG) filter-disks (12 $\mathrm{mm}$ in diameter, $10 \mu \mathrm{m}$ thickness, $2 \mu \mathrm{m}$ pores, inserted in frames) were subjected to oxygen-plasma for $2-3$ min (Z550; Leibold-Heraeus, Hanau, FRG; $10 \mathrm{~cm}^{3}$ at standard temperature and atmospheric pressure (STP) $\mathrm{Ar} / 30 \mathrm{~cm}^{3}$ (STP) $\mathrm{O}_{2}$ ) to clean and hydrophilize the surface in order to achieve optimal cell attachment. Before coating was performed, the membranes were autoclaved in distilled water for $40 \mathrm{~min}$ at $120^{\circ} \mathrm{C}$. For the cultivation of TII cells, one side of the filter was coated with $20 \mu \mathrm{L}$ sterile Matrigel $\overparen{M}\left(10 \mu \mathrm{g} \cdot \mathrm{cm}^{-2}\right.$; Serva, Heidelberg, FRG) while the other side, which was used for the cultivation of MEC, was coated with $20 \mu \mathrm{L}$ sterile collagen type 1 (10 $\left.\mu \mathrm{g} \cdot \mathrm{cm}^{-2}\right)$. For each coating procedure, the membranes were incubated for $3 \mathrm{~h}$ at $37^{\circ} \mathrm{C}$ in a humified atmosphere. Prior to use, the coated membranes were washed briefly in PBS. Matrigel coating of polycarbonate membranes for TII cells was performed for LAI perfusion experiments only, whereas collagen coating for MEC was performed in all experiments.

Standard culture conditions. Rat TII cells $\left(10^{5}\right.$ cells $\left.\cdot \mathrm{cm}^{-2}\right)$ and bovine MEC $\left(5 \times 10^{4}\right.$ cells $\left.\cdot \mathrm{cm}^{-2}\right)$ were seeded in DMEM, 10\% FCS, $100 \mathrm{U} \cdot \mathrm{mL}^{-1}$ penicillin and $100 \mu \mathrm{g} \cdot \mathrm{mL}^{-1}$ streptomycin. Forty eight hours after plating, the medium was exchanged. Cells were maintained in a humified incubator (Heraeus, Hanau, FRG) with $5 \% \mathrm{CO}_{2}, 13 \% \mathrm{O}_{2}$ and $82 \% \mathrm{~N}_{2}$.

Immersion co-culture. Bovine MEC were seeded at a density of $10^{4}$ cells $\cdot \mathrm{cm}^{-2}$ on the collagen-coated side of pretreated membranes and incubated in standard culture medium for $24 \mathrm{~h}$. Thereafter, freshly isolated rat TII cells were seeded onto the opposite side of the filter and incubated in the same culture medium to allow adherence for $24 \mathrm{~h}$. After that period, the culture medium was changed. For routine immersion cultures, further medium exchanges were undertaken on all 4 days.

Perfusion-co-culture. TII and MEC on opposite sides of a polycarbonate filter, which were pretreated as for immersion culture, were placed in a perfusion-chamber [8] and supplied with fresh Leibowitz L-15 medium (Gibco, Eggenstein, FRG) supplemented with $10 \%$ FCS, $100 \mathrm{U} \cdot \mathrm{mL}^{-1}$ penicillin and $100 \mu \mathrm{g} \cdot \mathrm{mL}^{-1}$ streptomycin (flow $1 \mathrm{~mL} \cdot \mathrm{h}^{-1}$ ). The chamber temperature was kept constant at $37^{\circ} \mathrm{C}$ with an electrical heater. After 4, 18 and 32 days under normal perfusion conditions, membranes were removed, fixed and prepared for TEM examination (see below).

LAI perfusion co-culture. Membranes and cells were treated as for immersion co-culture until adherence of the TII cells, before being placed in a liquid-air chamber (figs. 3 and 4). Only the endothelial side of the filter was continuously supplied with serum-free medium [9] (modified): Leibowitz L-15 supplemented with $5 \mathrm{mg} \cdot \mathrm{L}^{-1}$ insulin, $5 \mathrm{mg} \cdot \mathrm{L}^{-1}$ transferrin, $10 \mu \mathrm{g} \cdot \mathrm{L}^{-1}$ epidermal growth factor (EGF), $1 \mu \mathrm{mol} \cdot \mathrm{L}^{-1}$ hydrocortisone, $0.5 \mathrm{mmol} \cdot \mathrm{L}^{-1}$ dibutyryl-cyclic adenosine monophosphate (cAMP), 25 $\mathrm{nmol} \cdot \mathrm{L}^{-1} \mathrm{Na}$-selenite, $100 \mathrm{U} \cdot \mathrm{mL}^{-1}$ penicillin and 100 $\mu \mathrm{g} \cdot \mathrm{mL}^{-1}$ streptomycin at a flow rate of $1 \mathrm{~mL} \cdot \mathrm{h}^{-1}$, whilst the TII cells were ventilated with air $\left(10 \mathrm{~mL} \cdot \mathrm{h}^{-1}\right)$. After 2, 4, 8 and 12 days under LAI perfusion conditions, membranes were removed and prepared for TEM examination (see below). 


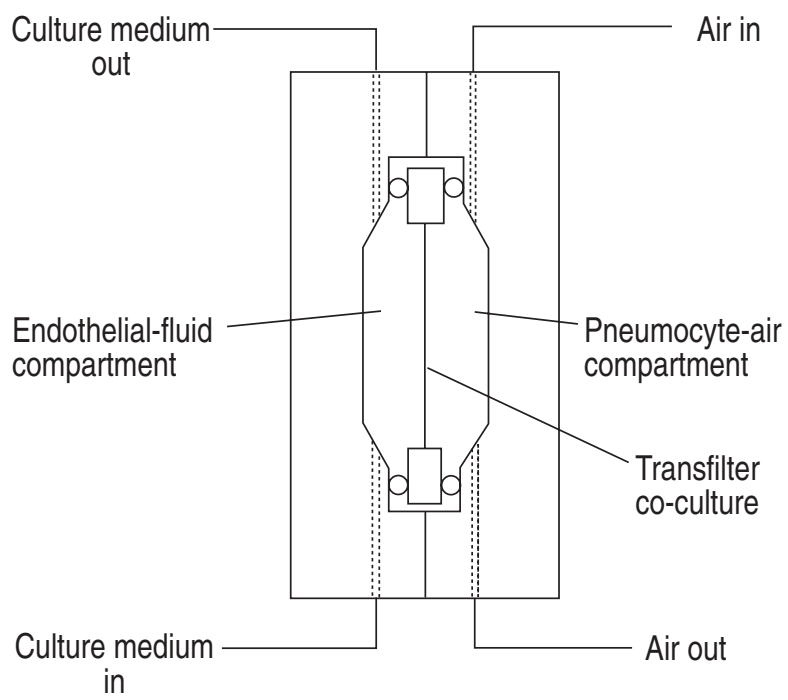

Fig. 3. - Schematic representation of the liquid-air chamber. In this chamber, the transfilter co-culture, which is represented in figure 4 , is orientated vertically. The outlet of the culture medium is situated at the top to displace any air bubbles and the air stream is orientated downwards to drain off leakage fluid, which can be collected for further examination.

\section{Determination of cell morphology and proliferation}

Silver staining procedure. In order to visualize the growth pattern of each cell type on polycarbonate filter, the adherent cells, after rinsing with 5\% glucose solution, were incubated with $0.1 \% \mathrm{AgNO}_{3}$ solution for $5 \mathrm{~min}$. After an additional washing with $5 \%$ glucose solution, cells were fixed for $10 \mathrm{~min}$ in $1 \%$ formaldehyde/PBS and then exposed to a strong light source for $15 \mathrm{~min}$. All steps were performed at room temperature.

Preparation for TEM. TII and MEC cells on opposite sides of polycarbonate membranes were fixed with $2.5 \%$ glutaraldehyde in $0.1 \mathrm{~mol} \cdot \mathrm{L}^{-1}$ cacodylate buffer $(\mathrm{pH} 7)$ for $1 \mathrm{~h}$ at $20^{\circ} \mathrm{C}$. After postfixation with $1 \%$ osmium tetroxide for $1 \mathrm{~h}$ at $20^{\circ} \mathrm{C}$, the cells were either contrasted with $0.1 \%$ tannic acid and/or $1 \%$ uranyl acetate for $1.5 \mathrm{~h}$ at $20^{\circ} \mathrm{C}$. The probes were dehydrated in graded series of ethanol and embedded in EPON-epoxy resin. Membranes were sectioned with a diamond knife on an ultramicrotome (Reichert \& Jung, Nussloch, FRG). The cross-sections were performed by horizontally positioning the embedded filter. Pale gold sections were picked up on 150-mesh coal-coated copper grids and stained with $10 \%$ uranyl acetate and $0.4 \%$ lead citrate. All chemicals for TEM preparation were obtained from Merck, Darmstadt, FRG. Specimens were examined in a JEOL 2000 FX II (Jeol Ltd, Japan) at $80 \mathrm{kV}$. Photographs were taken on Agfa Scientia (23 D 56) and Kodak electron image film (SO-163).

5-bromo-2'-deoxyuridine (BrdU) incorporation. In order to check whether the cells proliferated, they were incubated with $0.02 \mathrm{mM}$ 5-bromo-2'-deoxyuridine (BrdU) and $0.02 \mathrm{mM}$ deoxycytidine (dCyt) for $24 \mathrm{~h}$. Cells were fixed with ice-cold ethanol (20 min) and deoxyribonucleic acid (DNA) was denatured with $1 \mathrm{~N} \mathrm{HCl}(1 \mathrm{~h})$. Incorporated BrdU was detected with an anti-BrdU-mouse antibody (Partec, Arlesheim, Switzerland) and goat-antimouse-fluorescein isothiocyanate (FITC)-conjugate (Dianova Hamburg). To obtain the total cell number, they were additionally stained with Hoechst 33258.

All substances were obtained from Sigma Chemie, Deisenhofen, FRG, unless otherwise stated.

\section{Results}

When co-cultivating bovine MEC and rat TII as immersion-cultures the following structural characteristics were observed after 4 days of co-cultivation: the TII exhibited a monolayer growth pattern with intercellular junctions, classified as tight junctions from their ultrastructural appearance [10] and the presence of lamellar bodies. Moreover, characteristic signs indicated the onset of dedifferentiation processes [11], a flattened appearance (height $\approx 5 \mu \mathrm{m}$ ) and a change in shape and size of lamellar bodies (figs. 5a and 6). At that time, the MEC were still subconfluent. Often lamellar, round and densely-stained structures could be observed inside the filter pores (fig. 6).

\section{Fluid compartment}

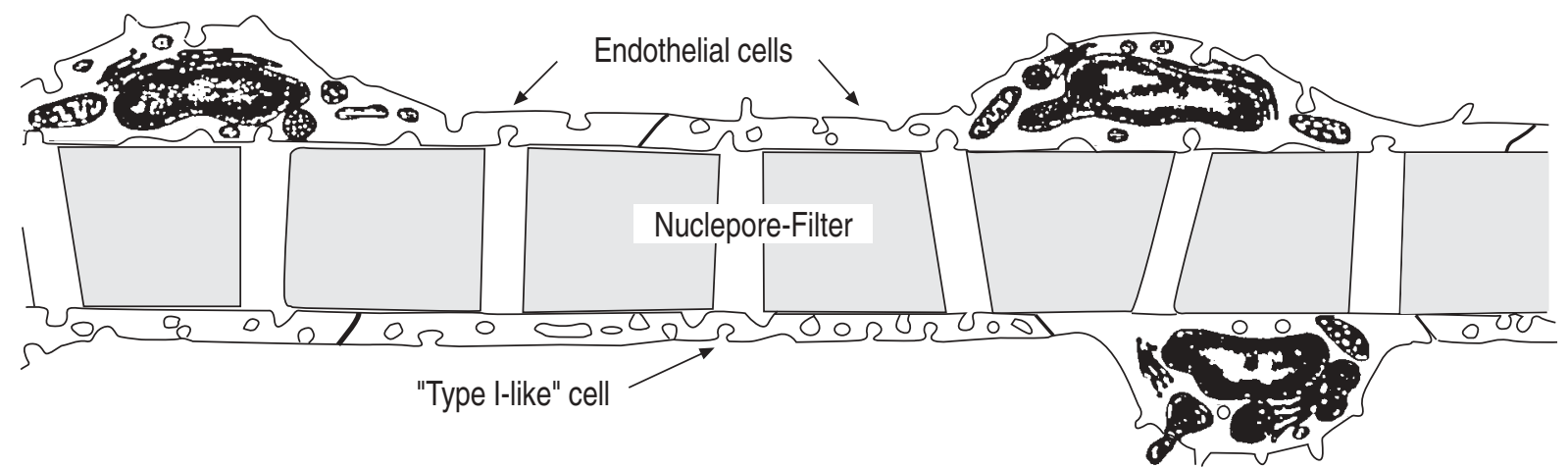

Air compartment

Pneumocyte type II

Fig. 4. - Model of the in vitro blood-air barrier. Whilst the microvascular endothelial cells (MEC) are cultured under perfusion conditions, the type II pneumocytes were "ventilated" with air. Both cell types are situated on opposite sides of a polycarbonate filter with 2 um pores. For the pneumocytes, the filter was coated with Matrigel $\overparen{\mathbb{M}}$, whereas the MEC side was coated with collagen type 1. 

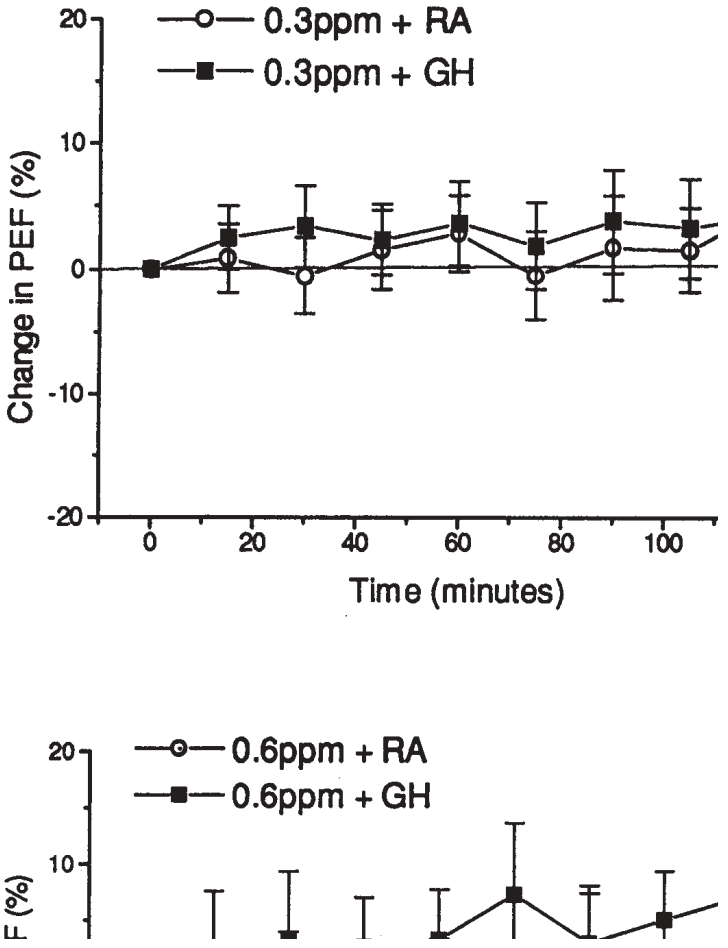

Fig. 5. - Effect of perfusion conditions on the growth of microvascular endothelial lung cells and type II pneumocytes in co-culture. a) After 4 days under perfusion conditions, the pneumocytes appear as a monolayer, whilst the endothelial cells on the upper side of the filter are still subconfluent. Dark spots inside the filter pores (arrow) are not cellular extensions but lamellar body-like structures, as revealed by electron microscopy (fig. 6). b) After 18 days of perfusion, only irregular growth with multilayer formation can be detected. Interestingly, lipid droplet-like structures can be observed at the former endothelial side (arrowheads), which might be due to the altered lipid metabolism of de-differentiating type II pneumocytes. c) After 32 days under perfusion conditions, an irregular multilayer growth is visible on both sides of the filter with remnants of dead cells. (Light microscopic examination of semi-thin sections internal scale bar $=20 \mu \mathrm{m}$ ).

These characteristic features for MEC and TII were observed both in immersion and perfusion co-cultures. The immersion co-culture was stopped as it differed from the situation found in vivo. After 5 days under serum supplemented perfusion conditions, the MEC remained proliferative $(18 \pm 3 \%)$ as checked by BrdU incorporation [12]; whilst after 8 days a large number of sprouting cells and cellular extensions was visible at the endothelial side of the perfusion co-cultures.

After more than 18 days of cultivation under perfusion conditions, a multilayer of cells could be observed on both sides of the filter (fig. 5b). No morphological distinction could be made between the pneumocytes and endothelial cells. Despite this fact, the cells showed distinct tight junctions and fibrillary material that was visible between the multilayer. There were only few lamellar-like structures present inside the filter pores, but rounded, densely stained, lipid droplet-like structures appeared at the former endothelial side of the filter. After 30 days of co-cultivation under perfusion conditions, an irregular multilayered growth was apparent on both sides

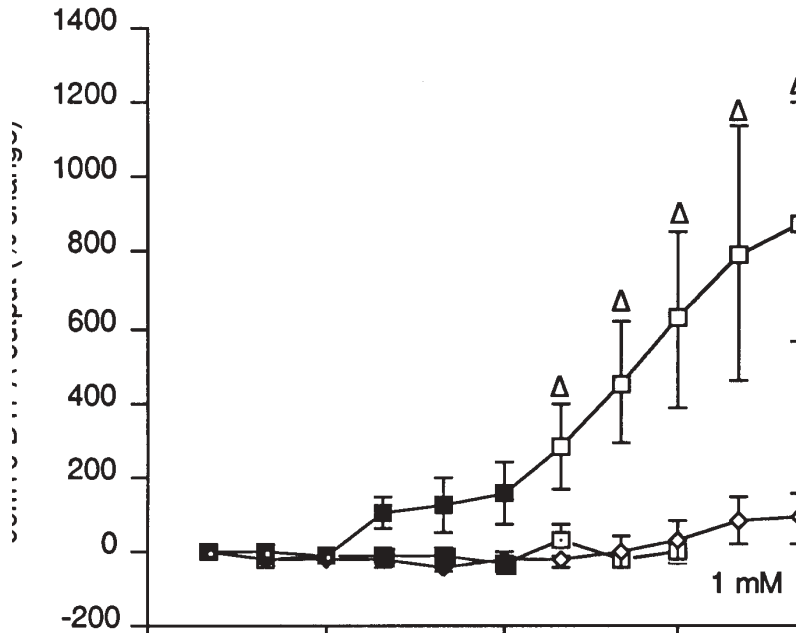

Fig. 6. - The figure shows a pneumocyte type II with signs of de-differentiation, as observed after 4 days of perfusion. Electron-dense, lamellar body-like structures appear inside the pores of the polycarbonate filter. (Transmission electron microscopy; internal scale bar $2 \mu \mathrm{m}$ ).

of the filter, with the remnants of many dead cells (fig. 5c). The lipid droplet-like structures concentrated on the surface of the fixation buffer as macroscopic droplets.

To avoid these signs of dedifferentiation, another approach was undertaken by using a defined serum free medium and MatrigelTM-coating of the TII cell side of the filter, which is proposed to be essential for the maintenance of TII cell differentiation [9]. As seen for serumsupplemented culture conditions, the pneumocytes remained quiescent during the first 4 days after adherence as checked by BrdU incorporation.

BrdU-incorporation and CFSE-staining were used to determine whether the defined serum-free medium altered the MEC with regard to growth and vitality. While the cells were able to grow to confluency the number of proliferative active cells was $24 \pm 4 \%$ and differed nonsignificantly ( $p>0.05$ ) from cultures grown under serumsupplemented conditions (fig. 7a). Furthermore, they appeared flattened and the cell boundaries could hardly be visualized by phase contrast microscopy. However, the typical cobblestone appearance was not changed, sprouting cells, multilayered growth and intracellular vacuolization, which were frequently observed under serum-supplemented conditions were not detectable (fig. $7 b)$.

In co-cultures under LAI perfusion conditions, the pneumocytes appeared as two morphologically distinct types after more than 8 days (fig. 8): 1) large, flat (cell height less than $1 \mu \mathrm{m}$ ) pneumocyte type I-like cells containing high numbers of caveolae but hardly any other organelles; and 2) cuboidal cells with characteristics of differentiated TII cells, marked by the presence of lamellar bodies and microvilli at their apical side. Electron-microscopic analysis revealed that remaining macrophages showed a specific adherence to TII cells, indicating the direct cellular interactions of these two cell types. This was not observable between macrophages and type I-like cells. These two pneumocyte cell types were interconnected by tight junctions and formed a macroscopically confluent monolayer. After 8 days of cultivation in the liquid-air chamber, the MEC showed a confluent 

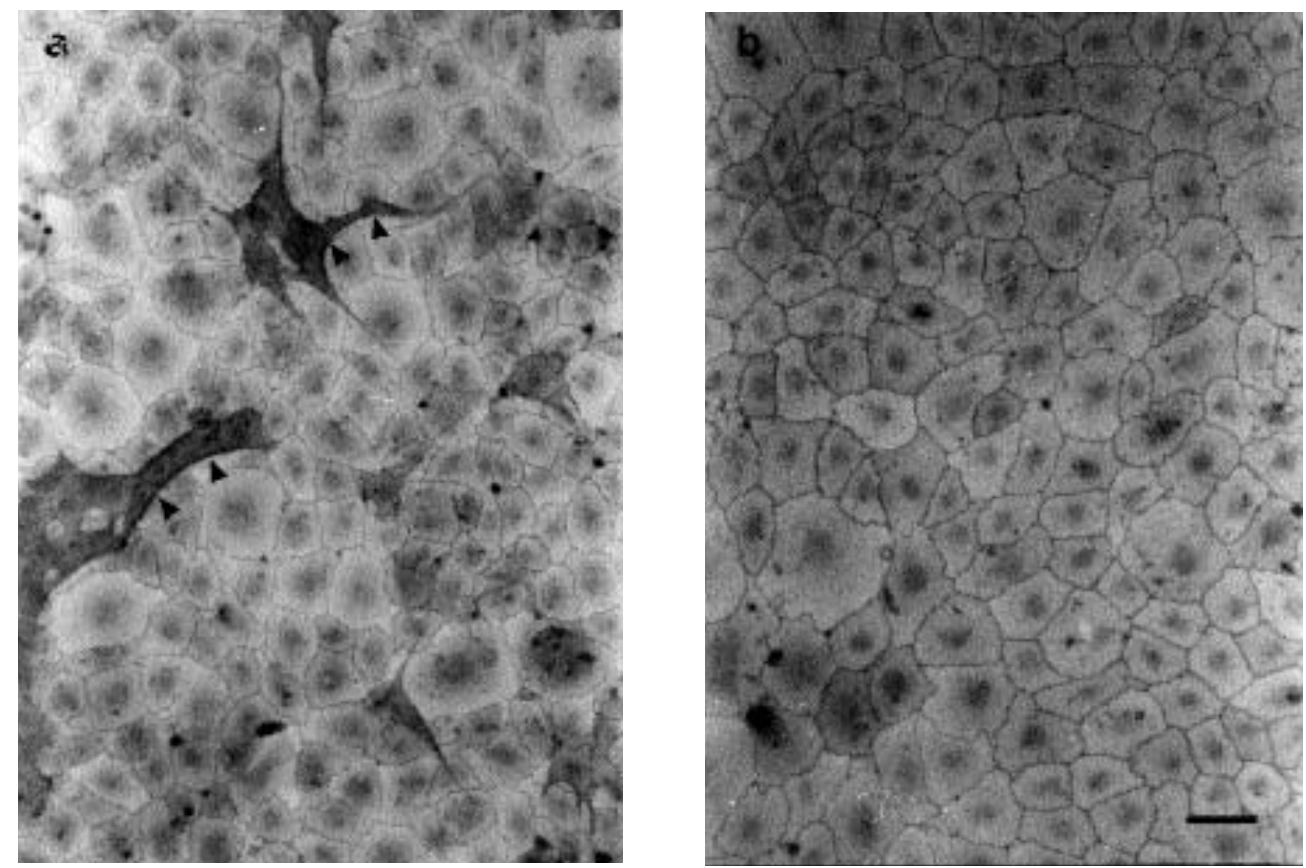

Fig. 7. - Effect of serum-free and serum-supplemented media on the morphology of the endothelial cells. a) When cultivated with serumsupplemented medium for more than 8 days, sprouting cells and overlapping cellular extension (arrowheads) could be observed. b) Under serumfree conditions, neither sprouting cells nor overlapping cellular extension could be detected. (The cell frontiers were visualized by silver staining and light microscopy; internal scale bar $=50 \mu \mathrm{m}$ ).
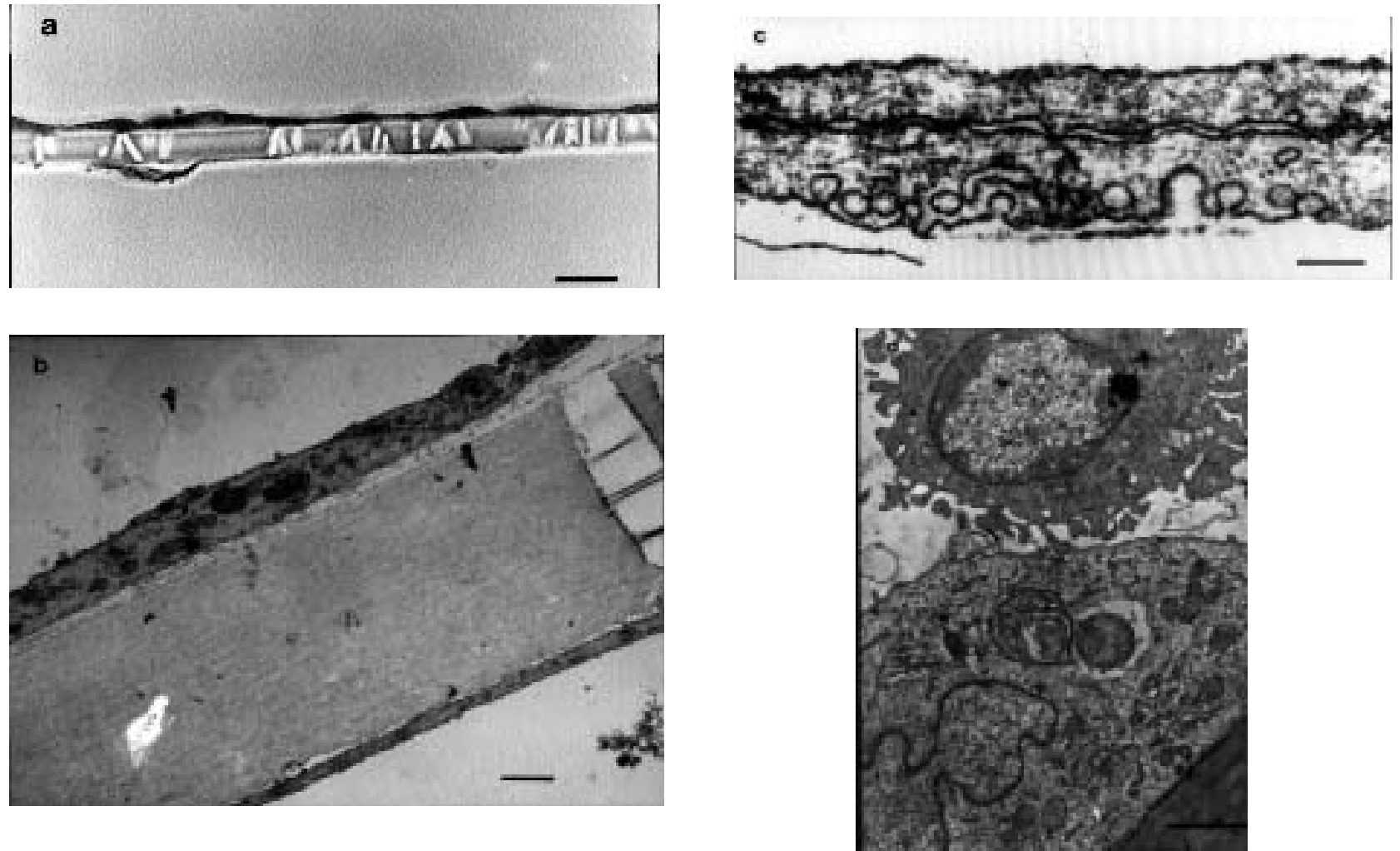

Fig. 8. - Effect of liquid-air interface cultivation on the growth of the co-culture. a) Semi-thin transection of a co-culture after 8 days. A confluent layer of endothelial cells is visible on the upper side of the filter, whilst the confluent layer of pneumocytes on the lower side is hardly detectable. (Light microscopy; internal scale bar $=20 \mu \mathrm{m}$ ). b) Electron microscopic image of a transection through a co-culture after 8 days. Large flat $(<1 \mu \mathrm{m})$ type I-like pneumocytes are visible on the lower side of the filter and endothelial cells on the upper side. Whilst the endothelial cells contain numerous organelles, the type I-like pneumocytes do not posses any larger ones. c) Two overlapping type I-like cells, with several electron-dense cell-cell contacts run parallel over the whole image. They contain high numbers of caveolae, whereas coated vesicles were not visible. d) After more than 10 days, cells which posses morphological characteristics of TII cells can be detected, often interacting with macrophages. (Transmission electron microscopy of semi-thin sections; internal scale bar $=2 \mu \mathrm{m}(\mathrm{b}$ and $\mathrm{d}$ ) and $0.2 \mu \mathrm{m}(\mathrm{c})$ ). 
monolayer with no signs of cellular vacuolization or degeneration. When compared to the type I-like pneumocytes, the endothelial cells had formed cellular junctions as well, but appeared higher $(3 \mu \mathrm{m})$ in section. Almost no cytoplasmic protrusions could be observed in the filter pores. In association with the morphological findings, it was observed that in a number of experiments $(n=12)$ under a transepithelial pressure of at least $200 \mathrm{~mm}$ water the leakage of fluid from the endothelial compartment to the epithelial side of the filter ceased after 3 days of cultivation in the liquid-air chamber.

\section{Discussion}

Up to now, two different approaches to lung cell cocultures have usually been reported. Either there has been no strict separation of the different cell types in a mixed cell culture [2], or there has been large diffusion distances and no possibility of cellular interaction due to the experimental design [1]. Although the transfilter co-culture model has been used to address other questions [3, 13, 14], to our knowledge a transfilter coculture has not yet been reported which closely mimics the blood-air interface with respect to the cell types (MEC and TII) or their geometric arrangement. Therefore, we developed a co-culture model in which the cells are strictly separated but located in close approximation, to minimize diffusion distances and to allow direct cellular interaction through the filter pores (fig. 4). Although we are aware of the 10-20 fold thickness of the polycarbonate filter in comparison to the basal membrane in vivo, it seems to be the most suitable filter at present because of stability, biocompatibility, the possibility of being autoclaved and ease of handling.

It has been shown that perfusion-cultures are able to maintain the differentiated status of cells in vitro [8]. Our observations of multilayer formation showed that neither co-cultivation with MEC nor perfusion conditions support the differentiated phenotype of TII cells in vitro. This might be due to the use of serum, as it has been shown that minimal amounts of serum components induce the dedifferentiation of TII cells in vitro $[15,16]$. Thus, for the culture of TII cells the use of serum-free medium should generally be recommended. So far, all attempts to cultivate TII cells under different conditions (medium, substrata, etc.) did not take into account that while growing at an liquid-air interface in vivo these cells produce their own superficial fluid. The cells are specialized in response to the luminal and basal microenvironmental conditions, which are the prerequisite for cellular functions, such as transport, synthesis and differentiation. Apart from the presence of different proteins and molecules in the alveolar fluid, its physiological $\mathrm{pH}$ differs markedly $(\mathrm{pH}=6.7)$ from that of the blood [17].

In order to obtain the highest possible cellular differentiation in vitro the function of TII cells to secrete their own apical fluid has to be taken into account. An apical-basal reorganization of endosomes in epithelial cells could be demonstrated when cultured under slightly different conditions of $\mathrm{pH}$ [18]. The $\mathrm{pH}$ of 7.4, as given by the culture medium at the luminal side of the cells in immersion and standard perfusion cultures, could be the reason for the basolateral exocytosis of lamellar bodies, as described previously [9].
The present study demonstrates, that TII and MEC can be kept in culture under LAI conditions. A subset of TII cells retained their differentiated phenotype for more than 10 days under LAI conditions. The co-existence of cuboidal TII cells and flattened type 1-like cells mimics the alveolar composition in vivo. The formation of a distinct monolayer on opposing sides of the filter, the observed intercellular junctions and the absence of obvious cellular injury indicates the advance of this method of cultivation compared to other culture conditions tested. However it remains to be elucidated whether the flattened cells are type I pneumocytes or just dedifferentiated TII cells. Macrophages which are frequently observed in direct contact with TII cells are thought to produce factors that induce the differentiated phenotype of TII cells [19]. We could not determine whether the differentiated phenotype was stimulated by macrophages or due to LAI cultivation. As no cellular interactions of these cell types could be observed in immersion cultures, this specific type of co-localization and cellular communication seems to be dependent upon the LAI co-cultivation conditions and is the subject of further investigation. The finding that no lamellar body-like structures were visible inside the filter pores when cultured under LAI conditions, favours our model system for the development of an artificial blood-air barrier.

The use of cell types originating from different species (rat/bovine) as presented here has, of course, to be considered as a potential restriction. To our knowledge, a continuous culture of differentiated rat microvascular endothelial cells over several passages or easy reproducible access to bovine TII cells has not yet been reported. Nevertheless, apart from direct cellular interactions which might be less efficient due to altered surface molecules, intercellular signalling by soluble molecules should be conserved enough in mammalian lungs. In order to design an easy-to-handle co-culture model, rat pneumocytes and bovine MEC provided easily obtainable and well characterized cells.

The liquid-air interface co-culture model presented here allows the cultivation of cells of the blood-air barrier under organotypic conditions and should be useful for cellular studies on the functional properties of the lung: 1) perfusion of the microvascular endothelial cell side to determine the transport of molecules over the blood-air barrier; 2) surfactant production in vitro can be studied without interference of culture medium or serum components; 3) simulation of pathological conditions, such as the formation of oedema; and 4) aspects of recruiting cells of the immune system to the alveoli by chemotactic substances. This may, thus, be an interesting alternative to animal models.

Acknowledgements: The authors thank U. Weber and S. Glock for excellent technical assistance and help with the photographs, and A. Mohr and R. Benz for the hydrophilization of filter material.

\section{References}

1. Adamson IY, Young L, King GM. Reciprocal epithelial:fibroblast interactions in the control of fetal and adult lung cells in culture. Exp Lung Res 1991; 17: 821-835.

2. Bingle L, Bull TB, Fox B, Guz A, Richards JR. Type II pneumocytes in mixed cell culture of human lung: a 
light and electron microscopic study. Environ Health Perspect 1990; 85: 71-80.

3. Mangum JB, Everitt JI, Bonner JC, Moore LR. Co-culture of primary pulmonary cells to model alveolar injury and translocation of proteins. In Vitro Cell Dev Biol 1985; 26: 1135-1143.

4. Dobbs LG, Gonzales R, Williams MC. An improved method for isolating type II cells in high yield and purity. Am Rev Respir Dis 1986; 138: 141-145.

5. Weston SA, Parish CR. New fluorescent dyes for lymphocyte migration studies. J Immunol Methods 1990; 133: 87-97.

6. Mason RJ, Williams MC, Clements JA. Isolation and identification of type II alveolar epithelial cells. Chest 1975; 67: 365-375.

7. Folkman J, Haudenschild CC, Zetter BR. Long-term culture of capillary endothelial cells. Proc Natl Acad Sci USA 1979; 76(10): 5217-5221.

8. Minuth WW, Stöckl G, Kloth S, Dermietzel R. Construction of an apparatus for perfusion cell cultures which enables in vitro experiments under organotypic conditions. Eur J Cell Biol 1992; 57: 132-137.

9. Kawada H, Shannon JM, Mason RJ. Improved maintenance of adult rat alveolar type II cell differentiation in vitro: effect of serum-free, hormonally-defined medium and a reconstituted basement membrane. Am J Respir Cell Mol Biol 1990; 3: 33-43.

10. N.B. Gilula. In: Cox RP, ed. Cell Communication. New York, Wiley, 1974; pp. 1-29.
11. Diglio CA, Kikkawa Y. The type II epithelial cells of the lung. IV. Adaption and behaviour of isolated type II cells in culture. Lab Invest 1977; 37: 622-631.

12. Gratzner HG. Monoclonal antibody to 5-bromo- and 5iododeoxyuridine: a new reagent for detection of DNA replication. Science 1982; 218: 474-475.

13. Fallier-Becker P, Betz E, Wolburg-Buchholz K, Fotev Z. Fibromuscular proliferates induced in vitro using a transfilter culture system. Res Exp Med 1991; 191: 11-25.

14. Weber E, Hämmerle H, Vatti R, Berti G, Betz E. Cocultivation of endothelial and smooth muscle cells on opposite sides of a porous membrane. Appl Pathol 1986; 4: 246-252.

15. Paine R, Joyce-Brady M, Brody JS, Brody AC. Serum accelerates the loss of type II cell differentiation in vitro. Am J Respir Cell Mol Biol 1990; 3: 311-323.

16. Tanswell AK, Byrne PJ, Han RNN, Edelson JD. Limited division of low-density adult rat type II pneumocytes in serum-free culture. Am J Physiol 1991; 260: L395-402.

17. Nielson DW, Goerke J, Clements JA. Alveolar subphase $\mathrm{pH}$ in the lungs of anesthetized rabbits. Proc Natl Acad Sci USA 1981; 78: 7119-7123.

18. Parton RG, Dotti CG, Bacallo R, Kurts I, Simons K. $\mathrm{pH}$-induced microtubule-dependent redistribution of late endosomes in neuronal and epithelial cells. J Cell Biol 1991; 113: 261-274.

19. Hunninghake GW, Brody M, Hampson F. Inflammatory mediators augment type II alveolar cell proliferation. Clin Res 1985; 33: 466A. 